\title{
LAVOURA ARCAICA E AS FORÇAS PRIMORDIAIS DO ROMANCE
}

\author{
Francisco Mateus Conceição ${ }^{1}$
}

Resumo: Neste artigo pretendemos analisar o romance Lavoura Arcaica a partir dos cinco principais elementos constitutivos da estrutura narrativa: enredo, personagens, espaço, tempo e narrador. Entendemos que, nessa obra, estes elementos incorporam, em sua máxima potência, o caráter moderno do romance, enquanto tensão e complexidade. Por este motivo, podem servir como porta de entrada para a análise de outros aspectos do universo da narrativa, como a memória e o poder patriarcal, que também serão objetos desta abordagem.

Palavras-chave: romance, memória; autoritarismo; subjetividade.

Abstract: In this paper we intend to analyze the novel Lavoura Arcaica according to the five major elements that constitute narrative structure: plot, character, space, time and narrator. We understand that in this novel these elements present their maximum potential in which may demonstrate the characteristics of the modern novel considering its tension and complexity. For this reason, they may serve as an invitation to the analysis of different narrative aspects like memory and patriarchal power that will also be objects of discussions in this analysis.

Keywords: novel; memory, authoritarianism, subjectivity.

\section{Introdução}

Antonio Candido, em $A$ personagem no romance argumenta que a revolução sofrida pelo romance no século XVIII consistiu numa passagem do enredo complicado com personagem simples, para o enredo simples (coerente, uno) com personagem complicada (1987, p. 60-61).

Essa concepção do romance moderno parece-nos apropriada para refletirmos sobre Lavoura Arcaica, de Raduan Nassar. Pode-se considerar que há, nessa obra, um único núcleo episódico: a trajetória de André em busca de afirmação em seu núcleo familiar. Por extensão à simplificação do enredo, há, também, uma reduzida galeria de personagens, constituída pelos componentes da família de André (o pai, a mãe, seis irmãos e o avô) e uma prostituta com quem vive sua iniciação sexual. Mas é nestes,

1 Mestre em Literatura Brasileira (UFRGS); doutorando em Estudos Literários (UFSM). Email: fmfranciscomateus@gmail.com. 
especialmente no personagem principal, que o foco de atenção da narrativa recai, analisando suas relações com o conteúdo do enredo. De outra parte, o espaço e o tempo não são meros referentes da narrativa, mas, como procuraremos demonstrar, um campo de disputa de significado entre a voz da tradição familiar, representada pelo pai, e a de André, o personagem principal. Este, através da ação narrativa, procura organizar e registrar a memória pessoal e coletiva.

\section{O diálogo com narrativas clássicas}

O enredo deste romance é reduzido aos elementos essenciais e suficientes para colocar em ação a análise da subjetividade do personagem principal. Mas há, sim, a história de André, desde a infância até a adolescência, da qual podemos assinalar alguns momentos marcantes: na infância: apego à mãe e religiosidade, ambos expressos pela corporalidade; na adolescência, iniciação sexual em uma casa de prostituição, afastamento da casa da família, isolamento na casa antiga, relação amorosa com a Ana (irmã), partida do local e fixação em um quarto de pensão, diálogo com o irmão que irá resgatá-lo, retorno à família, enfrentamento discursivo com o pai, festa de seu retorno, dança sensual da irmã, assassinato de Ana pelo pai.

Esse enredo ecoa narrativas tradicionais. A volta do filho pródigo, sugerida estruturalmente, é explicitada quando André debate com o pai:

- Meu coração está apertado de ver tantas marcas no teu rosto, meu filho; essa é a colheita de quem abandona a casa por uma vida pródiga.

- A prodigalidade também existe em nossa casa. (NASSAR, 2009, p. 156)

Essa passagem abre a narrativa do debate com o pai, antecedida por uma linha em branco, a alertar que fora mais amplo e que, para a memória de André, ele possui significado maior daí para diante. O pai refere-se à história do filho pródigo para extrair daí seu ensinamento, que é rechaçado pelo filho, apontando que na família também há prodigalidade. O filho pode estar aludindo à própria questão social, afinal, no núcleo isolado da família há alimento para todos, mas no entorno "muitos trabalham, gemem o 
tempo todo, esgotam suas forças, fazem tudo o que é possível, mas não conseguem apaziguar a fome" (NASSAR, 2009, p. 157).

Mas o discurso tortuoso de André também remete a outra forma de prodigalidade: a do exercício do poder. Mais adiante expressará que desejava tão somente seu "lugar na mesa da família”. E tornará claro que esse lugar simbólico extrapola o sentido do alimento do corpo. Para André, se tivesse que "sentar à mesa só com esse fim", era preferível alimentar-se de "um pão acerbo" que lhe "abreviasse a vida" (NASSAR, 2009, p. 159). Fica evidente que acusa o excesso de poder paterno, autoritarismo que afirma os eleitos e joga na obscuridade os demais.

De outra parte, nega, em outro momento da narrativa, que tenha saído em busca de realização, através dos prazeres de uma vida de excessos, declarando que "já sabia desde a tenra puberdade quanta decepção me esperava fora dos limites da casa" (NASSAR, 2009, p. 67).

Por este viés, André não vai à procura de outro mundo, antes engendra uma fuga provisória de casa, como gesto de enfrentamento à ordem familiar, na esperança, ainda, de fortalecer-se dentro dela. Por isso, houve claramente de seus "anseios" a voz que lhe diz "estamos indo sempre para casa" (NASSAR, 2009, p. 34). Visto de fora, pelo pai, é o filho pródigo, mas da perspectiva de sua subjetividade, a condição é inversa. Ainda, ele não retorna como o filho que, enfim, se converte aos valores da família. É resgatado pelo irmão e curva-se, parcialmente, ao poder desta, sem que haja essa transformação. De maneira que sua história remete a essa narrativa clássica para subvertê-la.

Outra narrativa clássica que está subjacente à de Lavoura Arcaica é Rei Édipo. Há, efetivamente, um conflito edipiano nessa narrativa. A relação afetiva de André com sua mãe possui forte conotação erótica. Veja-se:

(...) só esperando que ela entrasse no meu quarto e me dissesse muitas vezes "acorda, coração" e me tocasse muitas vezes suavemente o corpo até que eu, que fingia dormir, agarrasse suas mãos num estremecimento, e era então um jogo sutil que nossas mãos compunham debaixo do lençol, e eu ria e ela cheia de amor me asseverava num cicio "não acorda teus irmãos, coração, e ela depois erguia minha cabeça contra a almofada quente do seu ventre e, curvando o corpo grosso, beijava muitas vezes meus cabelos(...).(Nassar, 2009, p. 25) 
Ao amor da mãe contrapõe-se o conflito com a ordem paterna. Ordem frente à qual André adota a tática da evasão: a religião, a natureza, o amor da irmã, o afastamento da casa e da família. Como Édipo, não pode fugir ao seu fado e, por isso, sempre que foge é para casa que está indo. Para o embate discursivo com o pai, cujo desdobramento será trágico.

\section{A complexidade do personagem principal}

O movimento espaço-temporal de André evoca, em um primeiro momento, a trajetória do herói mítico. Para Joseph Campbell (1988), há três momentos principais nessa trajetória: partida, iniciação e retorno. Destes, dois estão explícitos na narrativa, o afastamento e o retorno, restando a dubiedade em torno da iniciação.

Com relação à partida, o processo narrativo tem início com o personagem afastado do espaço familiar. A partida da família teria se realizado, antes, em direção à tapera, e, posteriormente, em direção à pensão interiorana. Mas há, ainda, outros momentos de afastamento, obscuros e cotidianos, o que é compatível com a complexidade do personagem moderno. Referimo-nos aos momentos em que, durante os festejos, se distancia da família, isolando-se na mata, em busca de abrigo e comunicação com as forças naturais, bem como, a suas aventuras noturnas, quando se inicia sexualmente, em uma casa de prostituição. Neste último caso, o rompimento das fronteiras do espaço familiar é fortemente assinalado.

(...) me remetendo às noites derradeiras em que minha sanha se esgueirava incendiada da fazenda, trocando a cama macia lá de casa por um duro chão de estrada que me levava até a vila, sem receio das crendices noctívagas que povoavam aquele curto trajeto, assustando com meu fogo a cruz calada á beira do caminho, assim como as histórias assombradas mal escondidas pelos ferros do portão do cemitério por onde eu passava, conduzido e sempre fortalecido por minhas reflexões profanas de adolescente. (NASSAR, 2009, p. 68-69)

Pode-se dizer, portanto, que o afastamento até a pensão interiorana configura a explicitação de um processo que o personagem vinha desenvolvendo, há mais tempo, de maneira discreta ou dissimulada. Processo que, no seu conjunto, propiciou a iniciação 


\section{Literatura e Autoritarismo}

sexual, seja enquanto prazer físico, na relação com a prostituta, seja enquanto paixão amorosa, na relação incestuosa com Ana. Não há, porém, nenhuma epifania, como na trajetória dos heróis míticos.

André foge à crença em uma mediação transcendental, cujo molde familiar não responde às suas inquietações, buscando outra maneira, ainda difusa, de encontro consigo e com o Outro. Com isso, enfrentando a questão central para o herói moderno, conforme as palavras de Campbell: "Não o mundo animal, o mundo vegetal, nem o milagre das esferas; o mistério crucial é, em nossos dias, o próprio homem." (CAMPBELL, 1988, p. 375)

A caminhada subjetiva de André remete-nos ao conceito de herói problemático. De acordo com Georg Lukács (2000, p. 82):

O processo segundo o qual foi concebida a forma interna do romance é a peregrinação do indivíduo problemático rumo a si mesmo, o caminho desde o opaco cativeiro da realidade simplesmente existente, em si heterogênea e vazia de sentido para o indivíduo, rumo ao claro autoconhecimento.

O autor enfatizará que o autoconhecimento somente poderá ser vislumbrado, ou seja, apenas é permitido "alcançar um máximo de aproximação, uma profunda e intensa iluminação do homem pelo sentido de sua vida." (NASSAR, 2009, p. 82) Se a trajetória do personagem romanesco se caracteriza pela busca de sentido para sua vida, "seu conteúdo é a história da alma que sai a campo para conhecer a si mesma, que busca aventuras para por elas ser provada..." (NASSAR, 2009, p. 91)

No caso de André, ele está imerso em uma série de conflitos. Em primeiro lugar, há a própria cultura de imigrantes libaneses, em condição de relativo isolamento, tendo em vista que a família está no campo e os demais parentes na cidade. Ela adota o fechamento como tática de defesa, de maneira que o saber dessa tradição perde o espaço maior de atualização histórica, tornando-se rígido e tendendo ao esclerosamento. Além disso, afastado do grupo maior, ele não dispõe da macroestrutura social em que essa tradição se apoia, dependendo, de maneira quase exclusiva, da figura do avô e da voz do pai. De outra parte, há o mundo moderno ao redor frente ao qual o discurso familiar, por mais poderoso que seja, é ainda frágil. Neste personagem, portanto, se configura a tensão entre dois tempos históricos, o que o torna "demoníaco", ou seja, 
capaz de expressar outros conflitos latentes, dentre os quais destacamos o da sexualidade e o do autoritarismo patriarcal.

O romance narra sua busca por novos e autênticos valores, procura que permanece inconclusa. Ele não consegue erigir novos códigos, mas dessacraliza os velhos. Octavio Paz (1976, p.69), em abordagem que podemos aproximar à de Lukács, afirma que o romance é caracterizado por personagens que raciocinam e duvidam: "Épica de heróis que raciocinam e duvidam, época de heróis duvidosos, dos quais ignoramos se são loucos ou prudentes, santos ou demônios. Muitos são céticos, outros francamente rebeldes e anti-sociais e todos em aberta ou secreta luta contra o mundo".

André faz uma crítica implacável aos valores da família, mas não dispõe de estrutura para edificar uma nova ética. Por isso, sua postura é ambígua e contraditória, retirando daí sua riqueza, seu vislumbre de autoconhecimento:

Misturo coisas quando falo, não desconheço esses desvios, são as palavras que me empurram mas estou lúcido, pai, sei onde me contradigo, piso quem sabe em falso, pode até parecer que exorbito, se há farelo nisso tudo, posso assegurar, pai, que tem também aí muito grão inteiro. Mesmo confundindo, nunca me perco, distingo pra meu uso os fios do que estou dizendo. (NASSAR, 2009, p. 163-164)

Frente à irmã, fará um discurso mais claro, em tom de manifesto: "como vítimas da ordem, insisto em que não temos outra escolha, se quisermos escapar ao fogo deste conflito: forjarmos tranquilamente nossas máscaras, desenhando uma ponta de escárnio na borra rubra que faz a boca (...) apelemos inclusive ao deboche" (NASSAR, p. 133134).

A máscara, o deboche, o sarcasmo: características de personagens em flagrante oposição ao mundo que os engendrou; de personagens contraditórios, pois que negam esse engendramento que os constitui, mas só podem articular seu discurso a partir dele.

\section{O espaço sagrado e o profano}

No título dessa obra há uma imagem espaço-temporal. A lavoura da memória em que André lavra verbalmente apresenta-se, sem o fluir linear do tempo, cristalizada como 
imagem. Sua narrativa é um enfrentamento dessa imagem. Ele reage contra a sublimação espiritualizada do mundo concreto e evoca o mundo que seus sentidos percebem, entre os quais o elemento visual merece destaque.

Há um espaço central, a casa, que metaforiza a família, com seus códigos de valores e crenças. É nítida, nos sermões do pai, a oposição entre o espaço sagrado da casa e o exterior, bem como o empenho em distingui-los:

o mundo das paixões é o mundo do desequilibro, é contra ele que devemos esticar o arame das nossas cercas, e com as farpas de tantas fiadas tecer um crivo estreito, e sob este crivo emaranhar uma sebe viva, cerrada e pujante, que divida e proteja a luz calma e clara de nossa casa, que cubra e projeta de nossos olhos as trevas que ardem do outro lado(...). (NASSAR, 2009, p. 54)

Se compararmos o espaço da casa com um corpo, deduziríamos que o coração é constituído pela mesa da família. É dali que o discurso paterno é impulsionado repetidamente, para que circule pelas veias e células familiares. E é na mesa que se expressa, visualmente, o código de valores e a hierarquia familiar. Para além das palavras do pai, há um discurso puramente visual, silencioso e implacável. A descrição desses lugares e a interpretação, pelo narrador, de seu significado, é matéria do capítulo 24:

Eram esses os nossos lugares à mesa na hora das refeições, ou na hora dos sermões: o pai à cabeceira; à sua direita, por ordem de idade, vinham primeiro Pedro, seguido de Rosa, Zuleika, e Huda; à sua esquerda, vinha a mãe, em seguida eu, Ana, e Lula, o caçula. O galho da direita era um desenvolvimento espontâneo do tronco, desde as raízes; já o da esquerda trazia o estigma de uma cicatriz (...).

$\mathrm{O}$ avô, enquanto viveu, ocupou a outra cabeceira; mesmo depois da sua morte (...) seria um exagero dizer que sua cadeira ficou vazia. (NASSAR, 2009, p. 155)

A rígida ordem patriarcal não deixa frestas de dúvidas. O lado da esquerda é o não lugar, o que leva André a dizer que abandonara a casa porque queria um lugar à mesa. Por sua vez, a mãe ocupa o lado negativo da mesa, em razão da "carga de afeto". Mas, talvez, o que melhor sublinha esse poder patriarcal é o vazio da cadeira do avô. Significa o poder que se eterniza, para além do ciclo natural da vida, e que, nas relações da família, sustenta a força da outra cabeceira, a do pai. Ao autoritarismo da distribuição dos lugares sem a justificativa do discurso, soma-se o autoritarismo do lugar que já não tem corpo nem voz, sendo pura reverência da memória. Constituem-se, assim, às cabeceiras 
da mesa, os dois espaços sagrados, tendo à direita do pai os eleitos e, à esquerda, os renegados. Com isto, a ordem da família, afirmada verbalmente, expõe sua profunda fissura.

André está em processo de suplantação do espaço arcaico da família. Como no discurso do gênesis, o verbo faz-se realidade e ele nasce do barro.

(...) e meu verbo foi um princípio de mundo: musgo, charcos e lodo; e meu primeiro pensamento foi em relação ao espaço, e minha primeira saliva revestiu-se do emprego do tempo; todo espaço existe para um passeio, passei a dizer, e a dizer o que nunca havia sequer suspeitado antes, nenhum espaço existe se não for fecundado, como quem entra na mata virgem e se aloja no interior. (NASSAR, 2009, p.87)

Seu primeiro pensamento, e também sua ação, se volta para o espaço, que redescobre e refaz os sentidos, fecundando-o com o princípio do prazer e de sua humanização. Obviamente, esse processo será rechaçado pelo pai:

Cale-se! Não vem desta fonte a nossa água, não vem destas trevas a nossa luz (...) ninguém em nossa casa há de padecer de um suposto e pretensioso excesso de luz, capaz, como a escuridão, de nos cegar. (NASSAR, 2009, p. 167)

\section{O tempo mítico e o tempo vivido}

Conforme Paul Ricoeur (2010), o ser humano organiza o tempo em três estruturas principais: o tempo mítico, o histórico e o vivido. O tempo mítico é o tempo originário, anterior a todos, expresso pelos ciclos da natureza, sendo também denominado, em algumas situações, de tempo cosmogônico. Já o tempo histórico pressupõe a datação e necessita, para sua consecução, do tempo do calendário, que quantifica e subdivide o grande tempo em tempos menores. Este, sendo diferente do tempo mítico, possui pontos de apoio e derivação relativos a ele. $\mathrm{Na}$ origem desse tempo encontra-se o elemento mítico, através do movimento dos astros celestes, bem como do nascimento de um deus (Cristo, Buda...). Por isso mesmo, as religiões incorporam e sacralizam, com facilidade, o calendário moderno. Já o tempo vivido diz respeito à ocupação concreta do tempo histórico pelo ser humano. No caso de Lavoura Arcaica, trata-se das relações subjetivas com o tempo encetadas por André, em conflito com as ordenações do tempo mítico, verbalizadas no longo discurso ancestral do pai, do qual citamos um recorte: 
caprichoso como uma criança, não se deve contudo retrair-se no trato do tempo, bastando que sejamos humildes e dóceis diante de sua vontade, abstendo-nos de agir quando ele exigir de nós a contemplação, e só agirmos quando ele exigir de nós a ação. (NASSAR, 2009, p. 56)

O ser humano, visto nesta ordenação temporal, já possui seu tempo prefigurado, devendo compreendê-lo e segui-lo. Se for sábio nesse exercício de amoldamento ao tempo, ele construirá sua "própria imortalidade" (Nassar, 2009, p. 58), passando, também, a fazer parte das forças míticas. Para tanto, é necessário respeitar os desdobramentos cotidianos desse tempo, dentre os quais, o tempo das gerações.

Entre o tempo subjetivo de André e o mítico, interpõe-se o tempo histórico, localizável e concreto na vida da família. As festas e os sermões são rituais de atualização histórica do tempo mítico. E cabe destacar que a marcação objetiva do tempo pelo relógio é o equivalente, no plano narrativo, da quantificação oferecida pelo calendário. Ela dispõe de espaço central, através do avô, que se apresenta como o portavoz do tempo mítico em sua inter-relação com a história:

era ele na verdade que nos conduzia, era ele sempre apertado num colete, a corrente do relógio de bolso desenhando no peito escuro um brilhante e enorme anzol de ouro (...) nada naquele talo de osso brilhava além da corrente de seu terrível e oriental anzol de ouro.( NASSAR, 2009, p. 44-45)

Impaciente frente à sucessão desse tempo, que não the oferecia nenhuma probabilidade de realização, prenunciando-se somente ao filho primogênito, André cobra, imediatamente, seu lugar na família. Por isso, se seu primeiro pensamento foi em relação ao espaço, visando ocupá-lo, sua "primeira saliva revestiu-se do emprego do tempo" (NASSAR, 2009, p. 87), com a intenção de quebrar a ordem preestabelecida. Por isso, seu brado e seu desafio: "eu tinha simplesmente forjado o punho, erguido a mão e decretado a hora: a impaciência também tem seus direitos." (NASSAR, 2009, p. 88)

\section{A problematização do ato de narrar}

A problematicidade do personagem-narrador incide, logicamente, sobre a organização da narrativa. Inicialmente, chama-nos atenção a postura que o narrador 
adota frente ao seu relato, ao afirmar que "era tudo só uma questão de perspectiva, e o que valia era o meu e só o meu ponto de vista". (NASSAR, 2009, p. 109)

Ou seja, André não apenas fala a partir de sua perspectiva, como também despreza a preocupação ética em respeitar o ponto de vista contrário. Ele necessita anunciar sua voz e, para tanto, é necessário negar a ordem discursiva onde não encontrara espaço. A narrativa é um recorte de sua memória, uma construção discursiva em que procura, habilmente, refutar a fala do pai. Enquanto se afasta espacialmente da casa, ele se volta, pela memória, para esse discurso, e o enfrenta. E aqui cabe perguntar: de que tempo e lugar esse narrador nos fala?

Apoiando-nos na teoria de Gérard Genette (1995), podemos dizer que há na narrativa um narrador autodiegético de nível extradiegético. A condição de personagemnarrador explica a autodiegese, enquanto o nível extradiegético diz respeito à situação posterior (e exterior) do ato de narrar em relação ao narrado, assinalada na obra pelo tempo verbal nos pretéritos perfeito e imperfeito.

Essa exterioridade, no entanto, é problemática, podendo-se considerar que o narrador adota dois procedimentos principais. No primeiro, que abrange a maior parte da narrativa, conta sua história sem distanciar-se emocional e eticamente dela. Não há referência alguma às condições concretas dele, como se somente existisse enquanto voz narrativa. Mesmo o desenlace trágico da história não suscita, ao longo da rememoração, nenhuma referência, seja como remorso ou acusação, apesar de o personagem-narrador estar diretamente implicado nesse drama. Há, porém, em situações distintas, uma forma singular de marcação do ato narrativo. Referimo-nos a alguns capítulos, bem como parágrafos e expressões, que são estrategicamente apresentadas entre parênteses. Retomaremos essa questão ao tratarmos, no item a seguir, sobre a memória. Por ora, exemplificamos com a introdução de dois capítulos: "(Em memória do avô, faço este registro)" (NASSAR, 2009, p. 89) e "(Em memória de meu pai, transcrevo suas palavras)" (NASSAR, 2009, p. 193).

Esses dois exemplos possuem significado especial em razão do lugar estratégico que ocupam. Trata-se dos capítulos quinze (metade do romance), relativo ao avô; e trinta (o último capítulo), relativo ao pai. Nesses momentos, há uma consciência sobre o ato de 
organizar a memória narrativa. Ainda, os vocábulos "registro" e "transcrevo" demonstram que André conta sua história sob a forma escrita.

Não há, porém, evidências sobre tempo e lugar em que essa escritura é feita, de maneira que o narrador, e por extensão o romance, escapa ao molde realista. Entendemos, sob esse viés, que a narrativa possui um tom alegórico. O discurso de André pode ser visto como uma alegoria da rebeldia juvenil frente ao autoritarismo paterno; já o do pai como uma suma do discurso da tradição familiar. Neste sentido, é importante observar que as belas palavras do pai não condizem com o que o narrador chama de sintaxe "enrijecida". É como se sua fala transcendesse seu lugar de lavrador e que ele não tivesse completa propriedade sobre a mesma. É o que encontramos em uma das passagens mais sublimes do texto:

era ele que dizia provavelmente sem saber o que estava dizendo e sem saber com certeza o uso que um de nós poderia fazer um dia, era ele descuidado num desvio, olha o vigor da árvore que cresce isolada e a sombra que ela dá ao rebanho, os cochos, os longos cochos que se erguem isolados na imensidão dos pastos, tão lisos por tantas línguas, ali onde o gado vem buscar o sal que se ministra com o fim de purificar-lhe a carne e a pele, era ele sempre dizendo coisas assim na sua sintaxe própria, dura e enrijecida pelo sol e pela chuva, era esse lavrador fibroso catando da terra a pedra amorfa que ele não sabia tão modelável nas mãos de cada um. (NASSAR, 2009, p. 41-42)

\section{Literatura versus memória}

Neste romance há um contraste entre a memória individual de André e a memória coletiva do grupo ao qual faz parte. Referente à memória coletiva, ela tem na linhagem paterna seu veio mais anunciado, através dos sermões e do ordenamento familiar que impõe. O símbolo dela, pela ancestralidade, está no avô. Sua figura etérea, movendo-se pela casa, o associa com o mundo da espiritualidade:

era ele, Pedro, era ele nosso veio ancestral, era ele naquele seu terno preto de sempre, grande demais para a carcaça magra do corpo, carregando de torpeza a brancura seca do seu rosto, era ele na verdade que nos conduzia (...) era ele o guia moldado em gesso, não tinha olhos esse nosso avô, Pedro, nada existia nas duas cavidades fundas, ocas e sombrias do seu rosto. (NASSAR, 2009, p. 44-45) 


\section{Literatura e Autoritarismo}

$\mathrm{Na}$ outra ponta dessa tradição encontra-se Pedro, o filho primogênito, que assimila o discurso paternal. É referido diversas vezes por André como representante do pai, ele que fora "brindado com a santidade da primogenitura" (NASSAR, 2009, p. 108).

Mas existe outra forma de memória, expressa pelas festas, em que há dança, música e vinho. Essa memória não encontra lugar no discurso patriarcal, de maneira que age subterraneamente e também é moldada, a sua maneira, pelos personagens. Pode-se dizer que a relação incestuosa entre André e Ana atualiza o seu caráter dionisíaco. O pai não percebe o que ocorre diante de seus olhos, até ser informado por Pedro, quando intervém violentamente. A partir desse ato, outra memória coletiva se manifesta, através do lamento materno: "a mãe passou a carpir em sua própria língua, puxando um lamento milenar que corre ainda hoje a costa pobre do mediterrâneo: tinha cal, tinha sal, tinha naquele verbo áspero a dor arenosa do deserto" (NASSAR, 2009, p. 192).

De acordo com Michael Pollak (1989, p. 13), "um passado que permanece mudo é muitas vezes menos o produto do esquecimento do que de um trabalho de gestão da memória segundo as possibilidades de comunicação."

A paixão resgatará a memória dionisíaca, enquanto a dor recuperará a do lamento, explicitando discursos sufocados, que criaram, ao longo da narrativa, cumplicidades silenciosas.

Essa memória coletiva é filtrada pela memória individual de André. Nesse personagem-narrador existem dois planos memorialísticos. Há um plano que se identifica com a memória do personagem no tempo presente da ação, sem se descolar do nível intradiegético; e outro, claramente extradiegético, quando o narrador assume, ficcionalmente, a condição de memorialista. Conforme aludimos anteriormente, está marcado pelo uso de parênteses, sinalizando reflexão posterior ao narrado, para a qual propomos a seguinte classificação:

a) Intervenções do narrador

Trata-se de ações para reforçar o ponto de vista do narrador, como se este tivesse uma segunda voz. São os casos das intervenções rápidas e reiteradas para associar o irmão ao pai, como em: "era uma oração que ele dizia quando começou a falar (era o meu pai) da cal e das pedras de sal" (NASSAR, 2009, p. 16). 


\section{Literatura e Autoritarismo}

Também é o caso do comentário sobre o sermão do faminto. Neste, após narrar a história que o pai mais contava, André crítica a ideologia nela expressa e propõe uma nova versão, na qual o faminto cansa de esperar e agride o rei, que estava prestes a recompensá-lo por sua paciência.

b) Processos de organização da memória

Neste caso, há um acento sobre o trabalho de organização da memória. Nos capítulos dez e doze, ambos entre parênteses, o narrador discorre sobre a organização de sua memória pessoal. No capítulo dez, faz um longo inventário dos objetos da família, desde "uma pedra de moenda" até "uma fotografia castanha, nupcial" (NASSAR, 2009, p. 62-63). E conclui afirmando que "puxaria ainda muitos outros fragmentos, miúdos, poderosos, que conservo no mesmo fosso como guardião zeloso das coisas da família" (NASSAR, 2009, p. 63).

Conforme Paul Ricouer, existem rastros memoriais que não são testemunhos escritos, os quais "dependem igualmente da observação histórica", fazendo a "felicidade da arqueologia: cacos, ferramentas, moedas, imagens pintadas ou esculpidas, mobiliário, objetos funerários, restos de moradias, etc." (2007, p. 180).

É possível afirmar que André constitui, no "fosso" da memória, um museu dos objetos significativos na vida da família, cuidando dele com o zelo de um memorialista.

A relação entre os objetos e a vida familiar, articulando memória pessoal e coletiva, ficará mais evidente no capítulo doze, que retoma expressamente o dez: “(...) e é enxergando os utensílios, e mais o vestuário da família, que escuto vozes difusas perdidas naquele fosso (...) e vou puxando desse feixe de rotinas, um a um, os ossos sublimes do nosso código de conduta (...)" (NASSAR, 2009, p. 75).

Há na narrativa, também, o trabalho de organização da memória paterna. No final do capítulo 22, apresenta-se o excerto de um sermão paterno, entre aspas e antecedido por reticências, tendo ao final, entre parênteses, a referência: "Da mesa dos sermões" (NASSAR, 2009, p. 146). Nitidamente, o narrador representa o sujeito responsável pelo recolhimento da memória, tendo o zelo de referir e respeitar a fonte. A anteposição de reticências indica que a referência se aplica às demais pregações do pai. 
Se, neste caso, a fonte é referida ao final, entre parêntese, nos capítulos quinze e trinta, como mencionamos no item anterior, ela é feita no corpo do texto. Citar a voz do avô na metade do romance cumpre a função de conotar a centralidade de seu discurso na memória familiar. Vejamos por completo o curto capítulo:

(Em memória do avô, faço este registro: ao sol e às chuvas e aos ventos, assim como a outras manifestações da natureza que faziam vingar ou destruir nossa lavoura, o avô, ao contrário dos discernimentos promíscuos do pai - em que apareciam excertos de várias geografias, respondia sempre com um arroto tosco que valia por todas as ciências, por todas as igrejas e por todos os sermões do pai:

"Maktub.") (NASSAR, 2009, p. 89)

Apesar do tom solene, só há uma palavra do avô, como um "arroto tosco", traduzida em nota de rodapé como "Está escrito" (Idem, ibidem). Ele, que é visto pelo pai como um velho sábio, não tem quase nada a dizer, indicando que o saber primordial perdera sua força. $O$ registro de André acusa uma cisão entre o discurso supostamente originário do avô e o do pai, já contagiado por outras culturas. $\mathrm{O}$ julgamento depreciativo do discurso paterno tem um caráter polifônico, se aplicando à perspectiva do avô e à de André. Da parte deste, ao dizer que o discurso do pai vale menos que a palavra tosca do avô, acusa, mais uma vez, a inconsistência da fala paterna. Paradoxalmente, ele conclui a narrativa registrando as suas palavras. Um exame delas indica a afirmação do saber contemplativo diante da natureza, interpretando-a para aceitar seus desígnios. Fechar o romance, registrando a memória de tal saber, cumpre o significado de atestar que o mundo do pai está em processo de superação. E se André o combate no nível intradiegético, no processo extradiegético da escrita, ele preserva a memória desse discurso. Mediado por sua voz, vertido em outra forma discursiva, já sem o peso e a autoridade da tradição.

\section{Referências}

CAMPBELL, Joseph. O herói de mil faces. Tradução Adail Ubirajara Sobral. São Paulo, Círculo do Livro, 1988.

CANDIDO, Antonio. A personagem do romance. In: CANDIDO, Antonio et al. A personagem de ficção. São Paulo: Perspectiva, 1987. 


\section{Literatura e Autoritarismo}

Identidade, memória e representações culturais

GENETTE, Gérard. Discurso da narrativa. Tradução Fernando Cabral Martins. Lisboa: Vega, 1995.

LUKÁCS, Georg. A teoria do romance. Tradução José Marcos Mariani de Macedo. São Paulo: Duas Cidades; Editora 34, 2000.

NASSAR, Raduan. Lavoura arcaica. São Paulo: Companhia das Letras, 2009.

PAZ, Octavio. Signos em rotação. Tradução Sebastião Uchoa Leite. São Paulo: Perspectiva, 1976.

POLLAK, Michael. "Memória, esquecimento, silêncio". In: Estudos Históricos, Rio de Janeiro, vol. 2, n.3, 1989, p. 3-15.

RICOEUR, Paul. A memória, a história, o esquecimento. Tradução Alain François et al. Campinas: Editora da UNICAMP, 2007.

Tempo e narrativa 3. O tempo narrado. Tradução Claudia Berliner. São Paulo: Martins Fontes, 2010. 